\title{
Gekrönte Poeten und Gelegenheitsdichter in den Schönburgischen Herrschaften
}

\author{
von \\ OTTO-HEINRICH ELIAS
}

Eine Literaturgeschichte der schönburgischen Territorien muss mit dem Hinweis beginnen, dass nicht weniger als drei mit kaiserlichem Lorbeer ausgezeichnete Poeten hier geboren wurden, darunter einer der wichtigsten deutschen Dichter des Frühbarock, Paul Fleming. Über die beiden anderen Literaten namens Johann Pölitz und Johann Friedrich Käufler, die völlig vergessen sind, ließ sich mit einiger Mühe noch etwas Material zusammentragen. Die Verleihung des Titels Caesareus poeta laureatus (kaiserlich gekrönter Dichter) war die Nachahmung eines in der Antike üblichen Verfahrens während des Humanismus im 16. Jahrhundert, erst von oberitalienischen Städten und Universitäten praktiziert, dann von den römisch-deutschen Kaisern. ${ }^{1}$ Sie ist vergleichbar den heutigen Literaturpreisen; die Titelverleihung durch Kaiser Maximilian I. an Thomas Murner und Ulrich von Hutten entspricht also dem heutigen Nobelpreis für Literatur. In der Barockzeit erhielten die kaiserlichen Hofpfalzgrafen, also Juristen, die das Recht hatten, Notare zu ernennen, merkwürdigerweise auch das Recht, Poeten zu krönen. Daraufhin wurde der Titel immer häufiger verliehen und teilweise auch weniger wert, so wie es heute viele größere und kleinere Literaturpreise gibt. Trotzdem bedeutete diese Auszeichnung auch im 18 Jahrhundert immer noch, dass der betreffende Dichter in seiner Umgebung geschätzt wurde und ein großes Ansehen genoss. Außer diesen drei hervorgehobenen Poeten gab es in den westsächsischen schönburgischen Territorien noch viele Gelegenheitsdichter, Leute, die aus gegebenem Anlass und für besonderen Bedarf ein paar Verse zu Papier bringen konnten. Auch um diese Dichter werden wir uns auf den folgenden Seiten kümmern.

\section{Paul Fleming}

Dieser bedeutende Dichter wird hier nur insoweit behandelt, als sein Leben und sein Werk mit den schönburgischen Landen und der Familie der Landesherren verbunden waren, und auch zu diesem begrenzten Bereich kann hier fast nur die verdienstvolle, posthum veröffentlichte Arbeit eines schönburgischen Haushistorikers ${ }^{2}$ referiert werden. Eine Kurzbiografie ist hier aber am Platz. ${ }^{3}$ Paul Fleming wurde 1609 in der schön-

1 John L. Flood, Poets Laureate in the Holy Roman Empire. A bio-bibliographic handbook, 4 Bde., Berlin 2006, Introduction S. LIV. - Eine kurze Anzeige der schönburgischen Poeten lieferte bereits FRITZ ResCh, Gekrönte Dichter im Schönburgischen, in: Schönburgischer Hauskalender auf das Jahr 1930, S. 39 f.

2 Conrad Müller, Paul Fleming und das Haus Schönburg (Mitteilungen des Fürstlich Schönburg-Waldenburgischen Familienvereins Schloß Waldenburg 6), Waldenburg 1939. Müller lebte von 1858 bis 1935.

3 Flood, Poets Laureate 2 (wie Anm. 1), S. 570-574. - Das Folgende im Wesentlichen nach Müller, Fleming und das Haus Schönburg (wie Anm. 2) sowie nach HeINz Entner, Paul Fleming. Ein deutscher Dichter im Dreißigjährigen Krieg, Leipzig 1989. 
burgischen Residenzstadt Hartenstein geboren als Sohn des Lehrers Abraham Fleming, der nach seiner Hochzeit mit der gräflichen Kammerfrau Dorothea Müller den geistlichen Posten des Hofdiakons der Schlosskapelle erhielt. Da ein weiterer Aufstieg des Vaters in Hartenstein nicht möglich war, zog die Familie 1615 nach Topfseifersdorf bei Mittweida und schließlich 1628 in die schönburgische Residenz Wechselburg, wo Abraham Fleming bis zu seinem Tod als Hof- und Stadtpfarrer tätig war. Der Sohn Paul besuchte die Schule in Mittweida, wo er einen guten Lateinunterricht erhielt. In Leipzig absolvierte er ab 1623 das Grundstudium und schloss die Ausbildung als Mediziner 1633 mit dem Magistertitel ab. Die Lehre von der Dichtkunst gehörte damals zur Grundausbildung; der Student Fleming zeigte hier besonderes Interesse und außergewöhnliche Fähigkeiten. Als Thomaner wurde er beeinflusst von dem Thomaskantor Johann Hermann Schein, der nicht nur ein großer Musiker, sondern auch ein erfolgreicher Dichter war. Der Beruf des Arztes sollte dem jungen Mann den Lebensunterhalt sichern.

Da Leipzig in dieser Zeit zwischen den Schweden und den kaiserlichen Truppen sehr umkämpft war, verließ Fleming 1633 die Stadt und beteiligte sich an einer Gesandtschaft, die im Auftrag des Herzogs von Holstein-Gottorf einen neuen Handelsweg von der Ostseeküste über Russland nach Persien erschließen sollte, nicht als Arzt, sondern als Hofjunker und Truchsess, von dem erwartet wurde, die Reise poetisch zu gestalten. Der junge Literat hat während dieser Expedition tatsächlich viele Gedichte und Briefe geschrieben, aber das Buch, das die abenteuerliche Unternehmung öffentlich berühmt gemacht hat, verfasste sein älterer Freund und Reisegenosse Adam Olearius. ${ }^{4}$ Im Jahr 1635 verbrachten die Gesandtschaftsmitglieder einige Monate in Reval. Fleming erwarb hier gute Freunde und verliebte sich in Elsabe Niehusen, die Tochter eines wohlhabenden Kaufmanns. Als er 1639 aus Persien nach Reval zurückkehrte, hatte Elsabe allerdings einen Dorpater Professor geheiratet. Fleming, der den Posten eines Revaler Stadtarztes anstrebte, verlobte sich nunmehr mit ihrer jüngeren Schwester Anna Niehusen. 1640 promovierte der junge Dichter in Leyden (Holland) zum Doktor der Medizin. Auf der Rückreise nach Reval starb er in Hamburg im Alter von 30 Jahren an einer Lungenentzündung.

Obwohl Fleming nur knapp sechs Kinderjahre in Hartenstein verbracht hat, hat er diese Stadt und ihre Umgebung als seine eigentliche Heimat empfunden und seinem Namen oft ein Hartensteinensis oder eine entsprechende Abkürzung hinzugefügt. ${ }^{5}$ Auf der Reise nach Persien überfiel ihn am 9. November 1636 das Heimweh:

Ach, daß ich mich einmal doch wieder sollt erfrischen

an deiner reichen Lust, $d u$ edler Muldenfluß

$d a d u$ so sanfte gebst in pergichten Gepüschen,

da, da mein Hartenstein mir bot den ersten Kuß!

Wie jung, wie klein ich auch ward jener Zeit genommen

aus deinem süßen Schoß, so fällt mirs doch noch ein,

wie oft ich lustig hab' in deiner Flut geschwommen,

Mir träumte öfter noch, als sollt' ich um dich sein. ${ }^{6}$

4 Adam Olearius, Vermehrte Newe Beschreibung Der Muscowitischen und Persischen Reyse So durch gelegenheit einer Holsteinischen Gesandtschaft an den Russischen Zaar und König in Persien geschehen, Schleswig 1656.

5 Müller, Fleming und das Haus Schönburg (wie Anm. 2), S. 13.

6 „Elegie an mein Vaterland“; Paul Fleming, Deutsche Gedichte, 2 Bde., hrsg. von Johann Martin Lappenberg, Stuttgart 1865, Poetische Wälder IV, Nr. 48. Ein weiteres Gedicht mit dem Titel „Auf sein Vaterland Hartenstein im Voigtlande“ ist verlorengegangen. 
Der Dichter fühlte sich in Russland als der Mulde halbverlorener Sohn. ${ }^{7}$ Bei der gräflichen Familie, also bei der Witwe von Hugo II. von Schönburg-WaldenburgHartenstein (1559-1606) Katharina geb. Wild- und Rheingräfin zu Salm (1574-1654) und den Kindern aus den beiden Ehen des Grafen, waren die Kinder des Hofpfarrers und der ehemaligen Kammerfrau der Gräfin wohlgelitten. Taufpaten von Paul Fleming waren Gräfin Katharina selbst und ihr ältester Sohn, Hans Wolf von Schönburg (15941616). Der Sohn Christian Heinrich (1603-1626) und das 1606 geborene Fräulein Agnes waren seine Spielgefährten. ${ }^{8}$

Auf den Tod der jungen Gräfin Maria Juliane (1600-1629) dichtete Paul Fleming 1630 ein Leichengedicht in mehreren Teilen, ein Sonett an das hochedle Haus Schönburg und mehrere Elegien. Das ist seine erste gedruckte Veröffentlichung überhaupt: ${ }^{9}$

Schönburg, du schönes Haus, wie tustu ietzund klagen,

Indem ein großes Theil von Deiner Schönheit fällt

Und wird gerissen hin, darvon die Meißner Welt

Und jeder, der dich kennt, mit Trauern weiß zu sagen!

Wie sollte diesen Fall denn unbetrauert tragen

Ich, der ich obne dich in lauter Trauren bin,

Und gleichsam lebe tot! Ich, den du mich vorbin

mit Gnade dir erkauft? Drumb weil mir deine Plagen

und übergroßes Leid durch Herz und Seele geht,

Woblan, so nimm denn hin, der dir zu eigen steht

Mit allem, was er ist, die Schrift zu einem Pfande

Der reinen Dankbarkeit, die Schrift, die Tranerschrift,

Die mit dir weinen soll! Was förder dich betrifft,

So scheine schönes Haus, dem lieben Vaterlande!

Das ist das Muster eines Gelegenheitsgedichts: ${ }^{10}$ Aus gegebenem Anlass erscheint der Dichter, stellt sich und seine Gefühle gehörig in Positur, bedankt sich für bereits erhaltene Gnadenerweise, übergibt seinen Text und lobt den Adressaten. Die Formen solcher Dichtung hat er in Leipzig studiert, wo er auch andere Dichter kennengelernt hat, die er nachahmen kann. Es fällt auf, dass er keinen christlichen Trost spendet und stattdessen in vielen späteren Dichtungen die antike Götterwelt und Phraseologie bemüht, und das auf Deutsch, nicht auf Lateinisch - wobei er die lateinische Dichtkunst ebenfalls beherrschte.

Für den Poeten der Schönburger gab es in der folgenden Zeit Anlass für mehrere Totengedichte: für seinen 1626 im Krieg gefallenen ehemaligen Spielgefährten Christian Heinrich, für dessen vermutlich an der Pest verstorbene Schwester Elisabeth (1605-1630) und schließlich für den in der Schlacht bei Breitenfeld als sächsischer Rittmeister verwundeten und bald darauf gestorbenen Siegfried August (1596-1631) aus der Linie Penig-Forderglauchau. Letzterem galten die Verse:

7 Ebd., Sonette III, Nr. 28, Zeilen 9, 11.

8 Müller, Fleming und das Haus Schönburg (wie Anm. 2), S. 10 f.

9 Arae Schönburgica. Extinctae a Paulo Fläming Hartenstein[ensis], Leipzig 1631. Fleming, Deutsche Gedichte (wie Anm. 6), Poetische Wälder II, Nr. 1a.

10 Wulf Segebrecht, Das Gelegenheitsgedicht. Ein Beitrag zur Geschichte und Poetik der deutschen Lyrik, Stuttgart 1977, S. 571 u. ö. 
Er, der Tod, flob selbst vor dir,

Als du ibm nicht wolltest weichen,

Da er plötzlich sab erbleichen

Manchen Mann durch dein Rappier,

Wie von deiner kübnen Faust

Mancher Feind war angestraußt. ${ }^{11}$

Die Hartensteiner Grafen waren fromme Lutheraner. Auf Anregung seiner gräflichen Taufpatin hat Fleming ab 1631 in Leipzig geistliche Poeme über biblische Quellen veröffentlicht, ${ }^{12}$ Psalmen, ein Klagegedicht auf den Tod Jesu Christi und Preisgedichte für den Erlöser; in einem spricht er seine Patin als Mutter an. Da seine eigene Mutter 1616 gestorben war (der Vater ging zwei weitere Ehen ein), entspricht diese Anrede sicherlich seinen Gefühlen für diese Frau.

Ein erfreulicherer Anlass war die 1632 stattfindende Hochzeit ${ }^{13}$ seiner Freundin aus Kindertagen Agnes mit ihrem Vetter Christian von Schönburg-Wechselburg (1598-1664), zu welcher der Dichter mit den Taedae Schönburgicae Paulli Flemmingi, den „Schönburgischen Fackeln“, gratulierte. Der Wechselburger hatte im Krieg auf der katholischen Seite unter General Tilly mitgefochten, gewissermaßen als Teil seiner Universitäts- und Reisejahre. ${ }^{14}$ Die „Fackeln“ bestanden aus einer Widmung, einem lateinischen Teil und dem deutschen Frühlings-Hochzeit-Gedicht. Letzteres ist ganz und gar nicht christlich, von der geistlichen Funktion der Ehe ist nicht die Rede, umso mehr aber von antiken Göttern, Götterboten und Nymphen. Fleming entwickelt aus der Naturbeschreibung eine Philosophie der Begattung und eine Apotheose der Sexualität in einer festen Liebesbeziehung:
[...]
Die günstige Natur,
des Höchsten trene Magd weist Euch auff diese Spur.
Denn diß derselbe Zweck, an den wir alle dencken
Dabin wir Tag und Nacht die leichten Sinne lencken.
Wenn wir erwachsen seyn: Es muß geliebet seyn/
Soll dieses gantze Rund nicht kürtzlich geben ein.
[...]
Man kennet keinen Gott, der nicht geliebet hätte, dies ist der Nymphen Weg, sie lieben um die Wette.
[...]
Auch wir sind Göttern gleich durch unsrer Liebe Gaben,
Da meint ein jeder schon ein Himmelreich zu haben,
der fest und stete liebt, wenn die ibm, die er liebt
ein trenes Unterpfand der Gegenliebe gibt.

11 Merkwürdigerweise hat MüLler, Fleming und das Haus Schönburg (wie Anm. 2), S. 26 nicht erwähnt, dass es sich hier um den Schönburger handelt, der 1628 seinen Vetter Friedrich von Schönburg-Lichtenstein im Affekt erstochen hatte und der sich durch seinen Eintritt in das kursächsische Heer der gerichtlichen Verfolgung dieser Tat entzog. Fleming, Deutsche Gedichte (wie Anm. 6), Oden II, Nr. 1.

12 Ebd., Poetische Wälder I, Nr. 1 f.

13 Müller, Fleming und das Haus Schönburg (wie Anm. 2), S. 29 datiert die Hochzeit irrtümlich auf den 19. Februar 1633, sie fand aber 1632 statt und war schon für 1631 geplant gewesen. Fleming schrieb die Gratulationsgedichte bereits im Mai 1631; EntNer, Fleming (wie Anm. 3), S. 170. 

[...]
Wer wollte denn nicht lieben?
Wo wir nur seben hin, da werden wir getrieben
an dieses süße Werk, wer will denn nur ein Stein,
ein Stiefkind der Natur, ein Sichselbsthasser sein?

Dann wechselt das Versmaß. Das fünfstrophische Hochzeitslied hat Phöbus auf die Bitte des Dichters angefertigt:
[...]
Nun sie kömmt die schöne Brautl
der Cassandra müßte weichen/
Rom nichts schöners je geschaut/
Helena war kaum dergleichen/
Ja sie kömmt/ umbarmet Dich
Bräutgam/ gibt Dir eigen Sich.
Theures Paar/ vermengt die Brunst/
Liebt und gebet/ gebt und liebet/
Was Euch heißt des Himmels Gunst
Die Euch Zwey zusammen gibet
Eure Lieb sey immer neul
Lebet aller Trübsaal frey!

Der Dichter ist durch seine Beschäftigung mit der lateinischen Sprache und ihrer Schriftsteller zwar kein Anhänger der antiken Götterwelt geworden - Cupido, das sagt er selbst, ist der Poeten Spiel -, aber für den Mediziner und Naturwissenschaftler war vielleicht das Christentum nicht mehr die verbindliche Weltanschauung? Wir kommen noch auf diese Frage zurück.

Nach der Ernennung des Vaters zum Orts- und Hofprediger in Wechselburg fand die Familie 1628 einen neuen Lebensmittelpunkt. ${ }^{15}$ Paul lebte in dieser Zeit schon in Leipzig und kam nur noch besuchsweise in das neue Elternhaus, dem erst die zweite, dann ab 1634 die dritte Ehefrau des Pfarrers vorstand. Auch in Wechselburg hat er sich sehr wohlgefühlt und seinen Leipziger Freunden von der schönen Landschaft und den dort gebotenen kulinarischen Genüssen vorgeschwärmt. Müller zufolge entstand 1636 auf der Reise nach Persien in Astrachan auch eine beeindruckende Beschreibung Sachsens vor den Verwüstungen des Krieges. Dieses Gedicht stammt freilich nicht von Paul Fleming, sondern höchstwahrscheinlich von Conrad Müller selbst: ${ }^{16}$

15 Dass die Ernennung von Abraham Fleming zum Hofprediger von Agnes von Schönburg nach ihrem Umzug nach Wechselburg betrieben worden wäre, wie MüLLER, Fleming und das Haus Schönburg (wie Anm. 2), S. 15 annimmt, ist nicht möglich, denn die Berufung Abrahams lag fünf Jahre vor dieser Hochzeit. Eine hartensteinische Fürsprache ist freilich schon vor dieser Hochzeit denkbar.

16 Müller, Fleming und das Haus Schönburg (wie Anm. 2), S. 23. Es handelt sich vermutlich um eine absichtliche Irreführung der Leser, um einen literarischen Scherz. Dafür sprechen folgende Indizien: 1. Das Gedicht ist in Flemings publizierten Werken nicht enthalten; auch Müller gibt keine Quelle an; 2. Beide infrage kommenden Orte, Schilda (Landkreis Elbe-Elster) und Schildau (heute ein Ortsteil der Stadt BelgernSchildau im Landkreis Nordsachsen), liegen nicht an der Zwickauer Mulde und nicht in der Umgebung von Wechselburg; sie können deshalb keine Jugenderlebnisse Flemings begründen; 3. Schon der Ortsname Schilda lässt einen Schildbürgerstreich vermuten. Dass Müller hier einer Mystifikation aufgesessen ist, möchte ich bei seiner guten 
Namentlich da, wo die Mulde mit dampfenden Wellen der Wald teilt, Obne ein Hemmnis sodann durchflutet die grünenden Fluren

Und durch die Äcker von Schilda, dem schattigen, größer geworden

Wälzt ibre Wogen in breiterem Bett: da lacht erst die Erde.

Überall sich auf dem Boden die stattlichsten Häuser erbeben,

Wäbrend der Fluß an begüterten Dörfern vorbeiziebt

[...]

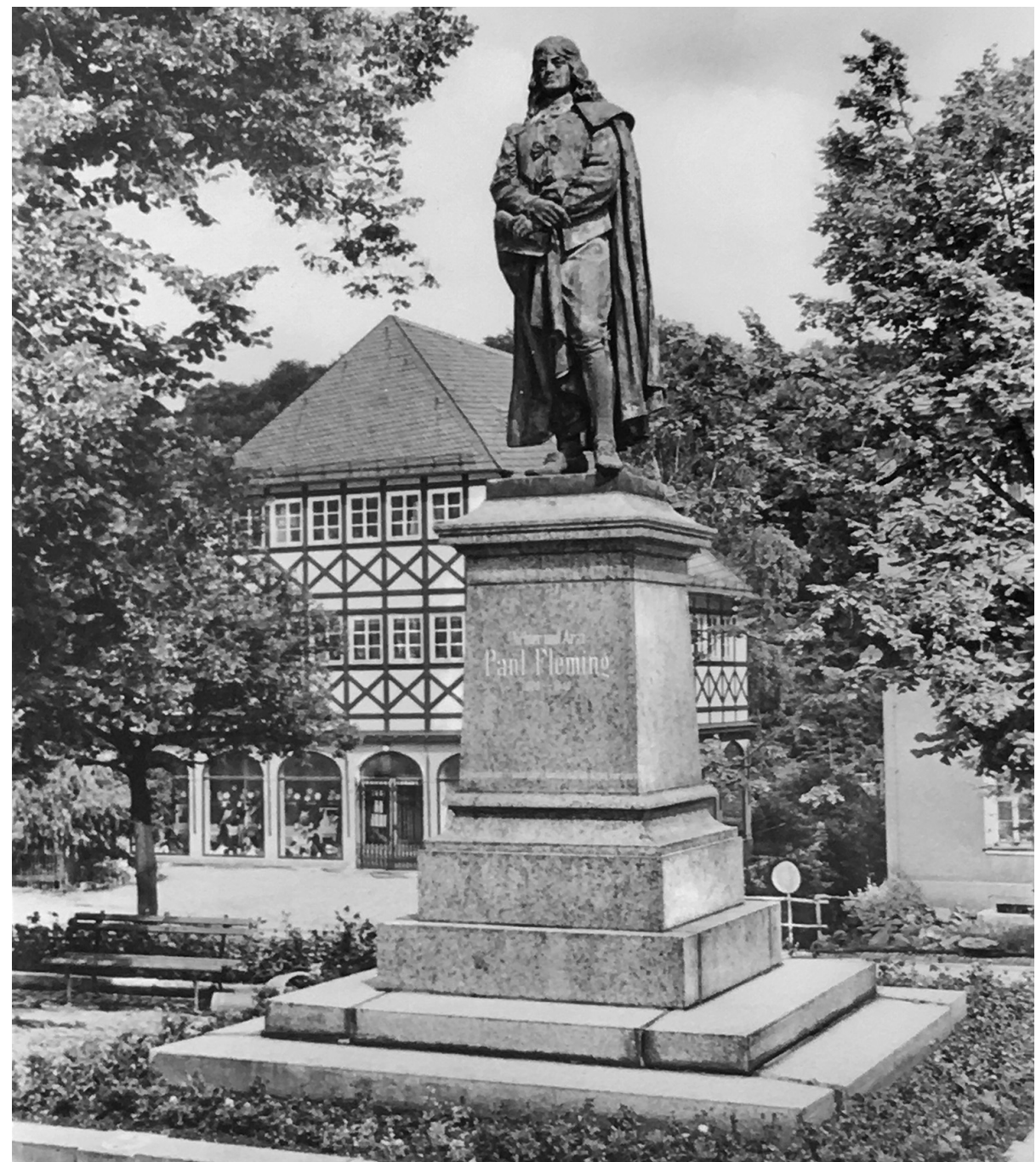

Abb. 1: Paul Fleming, Denkmal auf dem Marktplatz zu Hartenstein von Max Meißner, aufgestellt 1896.

Sachkenntnis ausschließen. Der sonst so seriöse Autor dürfte selbst der Mystifikator sein. 
Man wird annehmen dürfen, dass die schönburg-hartensteinische Familie den jungen Dichter auch materiell gefördert hat, sei es durch Zuschüsse zum Lebensunterhalt des Leipziger Studenten, sei es durch Honorare. Einzelheiten sind nicht bekannt. Grundsätzlich war der Vater zuständig. Ab 1628 bezog Fleming ein kurfürstliches Stipendium von 30 Gulden, das wohl auf schönburgische Empfehlung zurückging, aber 1632 auslief. ${ }^{17}$ In eben diesem Jahr haben die Kriegsereignisse alle anderen Quellen versiegen lassen, wohl auch ein Grund für den Abzug des jungen Mannes aus Leipzig. Hartenstein wurde sowohl von den Kaiserlichen als auch von den Schweden ausgeplündert, und auch der Vater in Wechselburg erlitt im Herbst 1632 einen militärischen Raubzug.

Eine besondere Anerkennung und Förderung, welche der Dichter aus Wechselburg erhielt, war seine Ernennung zum Poeta Laureatus Caesarensis, zum kaiserlich gekrönten Dichter. Diese fand vermutlich Anfang 1632 statt. Der Urheber war ein hoher Verwaltungsjurist, der schönburgische Rat und Landeshauptmann in Wechselburg Jeremias Aeschel (1593-1672), der 1628 Kaiserlicher Hofpfalzgraf geworden und infolgedessen zu dieser Verleihung befugt war. Es lagen zu diesem Zeitpunkt bereits einige den Schönburgern gewidmete, recht ausführliche Dichtungen vor, welche diese Ehrung als berechtigt erscheinen ließen. Der Titel sollte den jungen Mann wohl dem Hof in Dresden empfehlen, hat aber in dieser Hinsicht nichts bewirkt. Fleming hat ihn später nur selten geführt; er hielt ihn vermutlich für nicht sehr wertvoll. ${ }^{18}$

Abschließend soll noch einmal die Frage gestellt werden, wie der Dichter die von ihm so vielfältig beschriebene Welt gesehen hat. Diese Frage reicht freilich über unsere begrenzte Thematik weit hinaus. Conrad Müller war der Ansicht, dass sich Paul Fleming lebenslang einen „tieffrommen Gottesglauben“ im Sinne der Gräfin Katharina und seines eigenen Vaterhauses bewahrt hat. ${ }^{19}$ Seine häufige Beanspruchung antiker Götter und Sagen, sein Kokettieren mit römischem Hedonismus in der Nachfolge von Catull und Ovid wären demzufolge nur als eine literarische, seit der Renaissance übliche Attitüde einzuordnen. Wer nicht immer die Bibel ausschreiben wollte, bediente sich der antiken Kulisse und der dazugehörigen Statisterie. Wer dichtete wie Catull, lebte aber noch lange nicht wie Catull. Man muss nicht die Voraussetzung Müllers bejahen, um diese Folgerung zu akzeptieren. Ein anderer Aspekt betrifft Flemings Prägung durch die römisch-stoische Philosophie, durch Autoren wie Cicero, Seneca, Marc Aurel. Das Urteil von Heinz Entner lautet, dass bei dem Dichter beide Weltanschauungen koexistierend nebeneinander standen, aber auch Entner stellt in einigen Gedichten „krassen Nihilismus“ fest, reine Verzweiflung über die Kriegsgräuel, die dann wiederum in „nackte Lebensgier“ umgeschlagen sei. ${ }^{20}$ Auch das spricht nicht für eine christliche Position. Der Verfasser dieser Zeilen findet, dass Paul Fleming in den bedeutendsten seiner späteren Gedichte, in denen er sich dem Leser als Persönlichkeit ganz bewusst zu erkennen gab, ein von der stoisch-heldenhaften Anschauung geprägter Philosoph gewesen ist und dass er für diese Lebenshaltung einen großartigen poetischen Ausdruck gefunden hat.

17 Entner, Fleming (wie Anm. 3), S. 69.

18 Ebd., S. 208, 345.

19 Müller, Fleming und das Haus Schönburg (wie Anm. 2), S. 11.

20 Entner, Flemming (wie Anm. 3), S. 233, 351. 


\section{Gebrauchsdichtung}

Abgesehen von Johann Pölitz und Johann Friedrich Käufler, diesen beiden durch den ehrenden Titel hervorgehobenen Geistlichen, haben noch andere in Glauchau oder in den umliegenden Dörfern geborene oder amtierende Pfarrer Kirchenlieder verfasst. Urban Langhanß (1526-1570) aus Schneeberg amtierte in Glauchau als Kantor sowie von 1546 bis 1554 als Diaconus und kehrte dann nach Schneeberg zurück. Er schrieb die Lieder „Nun hört ihr Christenleut“ und das Neujahrslied „Nun laßt uns alle fröhlich sein“.21 Der zweite geistliche Liederdichter war Bartholomäus Crasselius (16671724), der Dichter vieler Kirchenlieder, darunter „Dir, dir Jehova will ich singen“. Er wurde in Wernsdorf bei Glauchau als Sohn des Schafmeisters Johann Krasselt geboren und von Johann Pölitz entdeckt, war nach dem Studium Informator, also Hauslehrer, auf dem Schloss in Glauchau und übte dann seinen geistlichen Beruf in Thüringen und im Rheinland aus. ${ }^{22}$ Wegen seiner pietistisch-strengen Anschauungen passte er nicht in die heimische Landeskirche. Das Schreiben lateinischer, später deutschsprachiger Texte und Gedichte gehörte in der Frühen Neuzeit bis in das 19. Jahrhundert hinein zu den Fertigkeiten, die viele akademisch Gebildete beherrschten und ausübten. Das meiste davon ist nicht überliefert und wieder untergegangen; manche dieser Wortschöpfungen verdienen aber auch heute noch unsere Anteilnahme.

Ein Beispiel ist die Inschrift auf dem Bildnis des Kaisers Karl V., das in der Kirche von Jerisau hängt. Der Monarch fand am 15. April 1547 auf dem Feldzug im Schmalkaldischen Krieg in Glauchau kein Quartier mehr und zog deshalb durch die nach ihm benannte Kaisergasse weiter in das nächstgelegene Dorf, wo er im Pfarrhaus unterkam. ${ }^{23}$ Angeblich blieb er zwei Nächte dort, wobei eine Rolle gespielt haben mag, dass sich der evangelische Pfarrer Georg Sörgel (Sorgel) als (heimlicher) guter Katholik herausstellte. ${ }^{24}$ Man nahm lange an, der Kaiser habe das Bild dem Pfarrer überlassen und es stamme von dem Hofmaler Jacob Woydt. Inzwischen weiß man aber, dass das Porträt von dem Glauchauer Kunstmaler Christoph Harbach 1612 der Gemeinde Jerisau in Rechnung gestellt worden ist. ${ }^{25}$ Die Distichen auf dem Bild, die vermutlich von dem damaligen Ortspfarrer Andreas Vogel stammten, lauten:

\section{Ille ego, qui quondam Carolus cognomine quintus \\ Dictus eram, rerum cum mibi summa foret, Dux belli, ut veni capiendi Saxonis ergo,}

21 ERnst Eckardt, Chronik von Glauchau. Eine historische Beschreibung der Stadt, verbunden mit einem Jahrbuche über die wichtigsten Ereignisse und einer Geschichte des Hauses Schönburg, Glauchau 1882, S. 385.

22 Eckardt, Chronik von Glauchau (wie Anm. 21), S. 482 f.

23 Ebd., S. 443.

24 Im Jahre 1835 wurden bei Bauarbeiten im Kanzelfuß der Jerisauer Kirche eine prachtvolle Kasel des frühen 15. Jahrhunderts sowie drei Messbücher entdeckt, die dort vermutlich anlässlich der Einführung der Reformation versteckt worden waren. ANKE WinKLER, Die Jerisauer Kasel. Beispiel eines hochmittelalterlichen, liturgischen Prunkgewandes, in: Museum und Kunstsammlung Schloß Hinterglauchau. Festschrift zur Wiedereröffnung der Kapelle „St. Marien“ zu Schloß Hinterglauchau 1999 (Schriftenreihe Museum und Kunstsammlung Schloß Hinterglauchau 11), Glauchau 1999, S. 6368. Sorgel war der letzte katholische und der erste evangelische Pfarrer in Jerisau; CARL Gotтloв Dietmann, Kirchen- und Schulgeschichte der Hochreichsgräfl. Schönburgischen Länder in Meißen [...], Breslau/Brieg/Leipzig 1787, S. 166.

25 Erich Berlet, Geschichte der Stadt Glauchau, Bd. 2,1: Glauchau von 1534 bis 1632, Glauchau 1934, S. VIII, 66. 


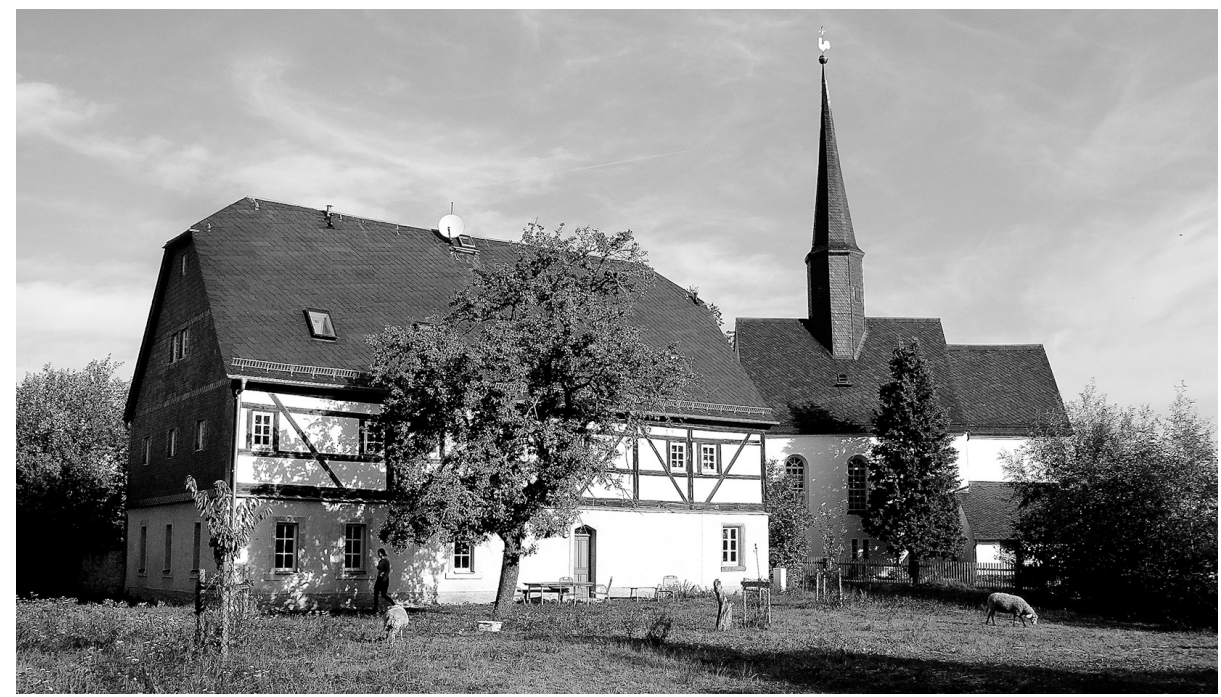

Abb. 2: Das 1661 erbaute Pfarrhaus und die Kirche in Jerisau.

Huc ego divertens hic habuit hospitium,

Quod si fama manet belli quod gessimus inde

Hoc locus et nostro nomine clarus erit,

Octava tunc luce dies surgentis Jesu

Cum lustris veto septimus annus erat.

(Ich bin jener, der, als er die Welt beherrschte,

den Namen Karl V. trug. Als ich, als Heerführer,

um den Kurfürsten von Sachsen gefangen zu nehmen,

hierher meinen Marsch nahm, hatte ich hier Quartier.

Und so lange, als man von dem Krieg,

den wir von hier aus führten, erzählen wird,

so lange wird auch dieser Ort

durch unseres Namens Gedächtnis berühmt bleiben.

Am achten Tage nach Ostern 1547.)26

Ein andere Sorte der Gelegenheitsliteratur sind die Vereinslieder, wie das von Pfarrer Gottlob August Werner in Lobsdorf 1737 verfasste Tafellied des Musikalischen Kränzchens in Glauchau, einem Verein zur Pflege der Kirchenmusik und der Geselligkeit, der seit 1636 bestand und in der Residenzstadt eine große Rolle gespielt hat:

Es grüne das Cräntzgen der sämtlichen Glieder!

Die Eintracht und Liebe beständig verbind.

Es weiche! Was dieser Verknüpfung zuwieder!

Es wachse das Gute, so man bierbey findt!

Es bleibe der Grund der Gesellschaft noch steben,

Wenn wir, mit der Zeit, nichts Verweßlichs mehr seben! ${ }^{27}$

26 Text und Übersetzung bei EcкArdt, Chronik von Glauchau (wie Anm. 21), S. 444.

27 Hans Germann, Die Geschichte des musikalischen Kränzchens in Glauchau und seiner Mitglieder, Leipzig 1935, S. III. 
Da mag es noch manchen Pfarrherrn gegeben haben, der die Eingangstür seines Pfarrhauses oder das Stammbuch eines Studienfreundes mit einem Vers verziert hat; Sammlungsarbeit ist hier nötig.

\section{Johann Pölitz}

Der zweite der durch die Lorbeerkrone hervorgehobenen Dichter wurde am 16. Mai 1644 in Bergsulza/Thüringen geboren und studierte in Jena Theologie und Philosophie. Den Kranz aufgesetzt hat dem 24-jährigen Studenten 1668 der Jurist Volkmar Happe (1628-1694), ein Mitglied der „Fruchtbringenden Gesellschaft“, der seinerzeit größten Sprachakademie und Vereinigung von Dichtern und Literaten. Happe war Kanzler und Oberkonsistorialpräsident in Weimar und als Hofpfalzgraf zu dieser Ehrung befugt. Wir erfahren aus diesem Anlass, dass Pölitz ein äußerst wertvoller und literaturbeflissener junger Mann gewesen sei. ${ }^{28}$ Es fällt aber auf, dass er erst sechs Jahre später ordiniert wurde, und zwar nicht in Sachsen-Weimar. Er war als Informator bei der Herrschaft Schönburg-Remse untergekommen. 1674 wurde er Pfarrer in Wernsdorf bei Glauchau; in demselben Jahr heiratete er am 20. Oktober das schönburgische Kammermädchen Sabina Förster. Das Pfarramt in Wernsdorf war gut dotiert, aber eine große Karriere hat er auch bei den Schönburgern nicht gemacht, er wurde nur noch 1689 zusätzlich zum Vize-Inspektor der neuerbauten Schule und Kirche in Ernstthal bestellt. In zweiter Ehe heiratete er am 10. Mai 1701 die schönburgische Kammerdienerin Anna Sabina Scharschmidt. ${ }^{29}$ Im Jahre 1703 starb er. Wir stoßen hier wieder auf den Umstand, dass sich Pfarrer mit herrschaftlichen Bediensteten verbanden und dieser Verbindung womöglich ihre Berufung verdankten. Ein solches Konnubium war im 17. Jahrhundert durchaus üblich.

Sein Kollege Gottfried Otto in Rottmannsdorf bei Zwickau, für dessen Hochzeitsfeier er 1670 eine Festschrift gedichtet hat, hatte ebenfalls eine schönburgische Kammerdienerin geheiratet, Judith Vitus. ${ }^{30}$ Von den Jugendgedichten, die zu seiner Krönung geführt hatten, ist nichts überliefert; aus dieser Zeit stammt nur das eben erwähnte lateinische Festgedicht: Venus Dormiens, In Taedis auspicatissimis Viri [...] Gottfridi Ottonis, Ecclesiae Rottmansdorfensis Pastoris dignissimi, Sponsi, Nec-non [...] Judithae [...], Liberae Baronissae de Schoenburg, Dominae in Glaucha E Waldenburg, Ec. Ec. hactenus ab officiis Camerariis [...] Andreae Viti, Accolae penes Tauchenses Integerrimi, Filiae perdilectae, Sponsae, Glauchae Misnicorum die XXII. Novembris [...] M.DC.LXX. ritè celebratis. Cygneae: Ebelius, $1670^{31}$ (Die Schlafende Venus. Hochzeitsfackel zur glücklichen Vermählung des aussichtsreichsten Herrn Gottfried Otto, des hochwürdigen Rottmannsdorfer Pfarrers, des Bräutigams, und Judith, der Agnes Beate, Baronin von Schönburg, Herrin von Glauchau und Waldenburg bisherige Kammerfrau, des Andreas Vitus, Beamter im benachbarten Taucha, geliebte Toch-

28 Konrad Händel, Die Vorfahren der Geschwister Paul, Elisabeth, Margarethe und Johanna Händel. Nach dem Forschungsstand vom 1. Mai 1939, In Auszügen neu herausgegeben und mit einer Einleitung und Ergänzungen versehen von Bernhard Pabst, Berlin 22008. Diese Publikation, die im Internet zugänglich ist, enthält viele Einzelheiten zur Biografie der beiden hier ausführlich behandelten Dichter, die den Kirchenbüchern entnommen sind. Ebd.; Germann, Musikalisches Kränzchen (wie Anm. 27), S. III.

30 Germann, Musikalisches Kränzchen (wie Anm. 27), S. III.

31 Ratsschulbibliothek Zwickau. Dieser und die folgenden Texte sind noch nicht digitalisiert. Ich danke der Ratsschulbibliothek für die Zusendung von Fotokopien. 


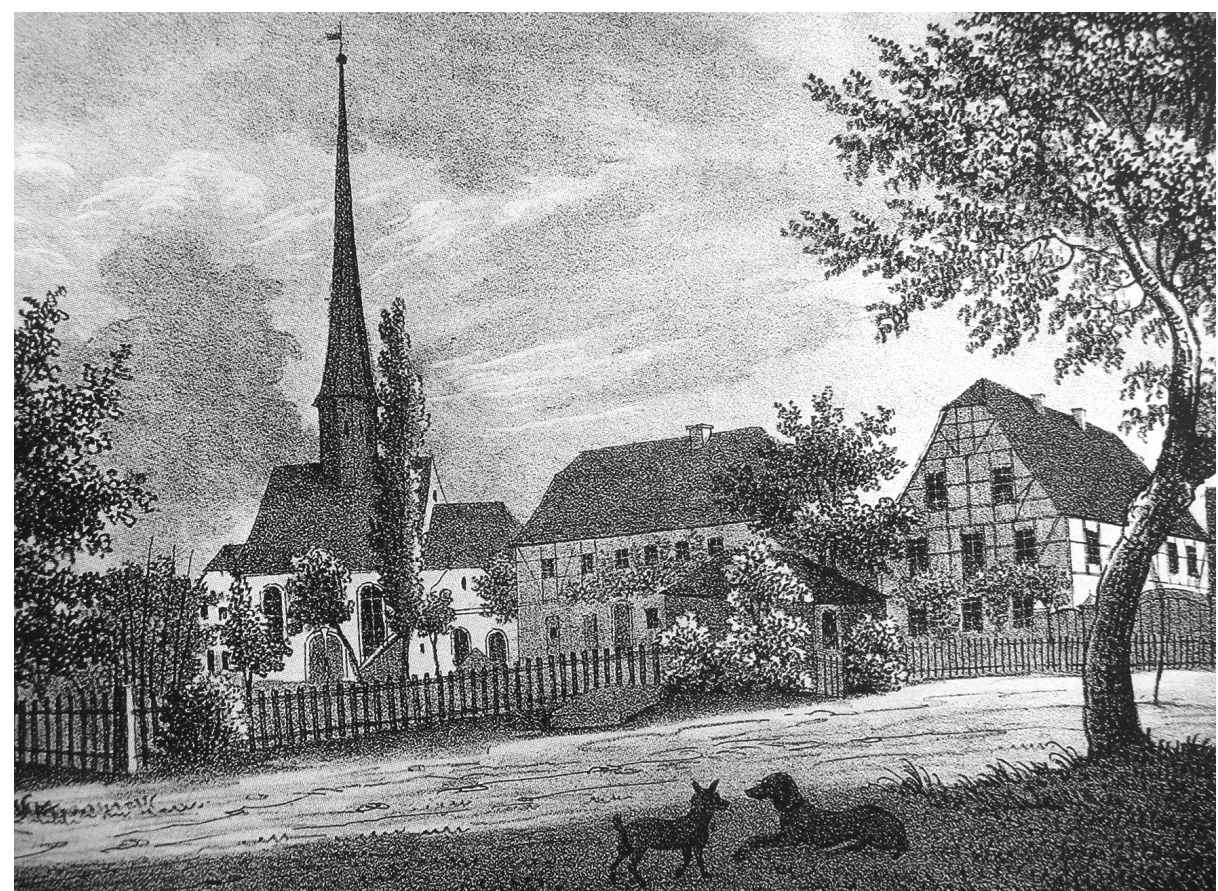

Abb. 3: Kirche und Pfarrhaus in Wernsdorf um 1840. Lithografie von I. H. Ketzschau.

ter, der Braut, zu Glauchau im Meißner Land am 22. November 1670 begangenen Feier).

Es handelt sich um einen aus wenigen Blättern bestehenden Druck. Das Titelblatt, das beherrscht wird von den versal gesetzten Vornamen des Brautpaares GOTTFRIED und JUDITH, ist druckgrafisch gestaltet. Es ist selbst ein Kunstwerk. Es folgen auf zwei Seiten neulateinische Verse und auf einer Seite ein endgereimter deutscher Text. Obwohl die Texte von einem Theologen an einen Theologen gerichtet sind, taucht der christliche Gott an keiner Stelle auf, vielmehr wird der antike Götterhimmel bemüht, soweit er thematisch zuständig ist. Den Kalender regelt das Sonnen-Kind mit seinen rothen Pferden, also Phöbus; Venus, Apollo, Cupido und Hymen sowie die Musen treten auf. Die Braut wird bei den Nymphen eingereiht:

Sie hegt ein keusches Hertz/ hat auch die andern Gaben/

Die sonst das Nymphen-Volck von vielen pflegt zu haben/

Sie liebt Bescheidenheit/ ist sauber in der Tracht/

Hält nichts auf grossen Stoltz/ nimbt ibrer wohl in acht.

$\mathrm{Zu}$ welchen sie noch wird das edle Kleinod setzen/

Und sich an Deiner Lieb und Huld allein ergetzen.

Nachdem die Tugend der Braut gewürdigt worden ist, werden die Freuden des Bettes in Aussicht gestellt. Von der religiösen Sinngebung der Ehe ist nicht die Rede. Auch dieser Dichter steht literarisch in antiker, nicht in christlicher Tradition. Das bedeutet nicht, dass Pfarrer Pölitz kein Christ gewesen wäre. Wie bei Fleming handelt es sich um eine literarische Attitüde, der Dichter übernimmt eine vorgefundene Form und schreibt sie fort. 
In den folgenden drei Jahrzehnten seines Lebens hat Pölitz nur noch zwei Gedichte für Hochzeitsfeiern drucken lassen, das heißt, er hat als Pfarrer in Wernsdorf das Dichten zur Veröffentlichung im Wesentlichen eingestellt. Beide Drucke umfassen jeweils vier Blatt und sind in zeitüblicher Weise grafisch gestaltet. Im ersten, 1679 einer Hochzeit im Hause Schönburg gewidmeten Opus, beruft er sich auf das Vorbild von Paul Fleming: Hymenaeum Flemingianum renovatum, b. t. Des Hartensteinischen Poeten/ Hn. D. Paul Flemings/ Erneuertes Liebes-Gedichte/ Von ibm erstlich bey des [...] Christian/ Herrn von Schoenburg/ Herrn zu Glaucha und Waldenburg/ ec. Mit [...] Agnesen/ Fraeulein von Schönburg/ Fraeulein zu Glaucha und Waldenburg/ ec. HochHerrl. zum Hartenstein/ Im J.C. 1632. d. 19. Febr. gehaltenen Beylager/ auffgesetzet; Itzo aber/ als Dem Hochberrl. Groß-Herr-Vater/ zur gluecklichen Nachfolge/ Der [...] Christian-Ernst/ Herr von Schoenburg/Herr zu Glaucha und Waldenburg/ ec. Mit [...] Juliana-Marial Fraeulein von Schoenburg [...] Fraeul. Der Niedern Graffschafft Hartenstein/ ec. Im J.C. 1679. d. 25. Novembr. gleichfals auff dem Schoenburg. Residentz-Hause Hartenstein Hochberrl. Beylager bielt/ zum theil widerholet/ und [...] glueckwuendschend ueberreichet/Von Johann Poelitzen/ K.G. Poeten/ und Freyberr. Schoenb. Pfarrern zu Wernsdorff. 32

Der deutsche Text ist ein nur leicht veränderter und stark gekürzter Auszug aus dem Gratulationsgedicht, das Paul Fleming 1631 der Hochzeit seiner Kindheitsgespielin Agnes gewidmet hat. ${ }^{33}$ Wo Fleming die antiken Götter und Halbgötter liebend und sich paarend tummeln lässt, mischt Pölitz ein paar alttestamentarische Helden darunter: Adam und Abraham, Simson und Jakob. Ansonsten übernimmt er Flemings grandiose Rechtfertigung des Paarungstriebes, der die gesamte Natur sowie die Götterund Menschengeschichte beherrscht und dem nun das Hochzeitspaar folgt. Selbst im heimischen Fluss Mulde wohnen attraktive Najaden und gratulieren.

Die offene Wiederverwendung eines fremden Textes lässt vermuten, dass die poetische Ader des Wernsdorfer Pfarrers versiegt war. Es folgt der lateinische Epilogus, ein Lebenslauf des Bräutigams in Prosa, der in Leipzig Theologie, die lateinische Sprache und andere Wissenschaften studiert hat und nun die Herrschaft in Hartenstein angetreten hat, um den edelsten römischen Kaisern Vespasian und Trajan nachzufolgen.

Das zweite Hochzeitsgedicht hat Pölitz zusammen mit dem Theologiestudenten Christoph Förster, seinem Schwager, verfasst. Es galt der Hochzeit seines Kollegen Johann Caspar Harrbach (1624-1705), der 1685 zum Superintendenten in Glauchau aufgestiegen war und 1686 in zweiter Ehe eine schönburgische Kammerfrau heiratete: Asmation didymon, Quo Viro Pl. Venerando, Amplissimo [...] Johanni-Casparo Harrbachio, Ecclesiae Glauchaviensis Pastori, Ejusdemque Ac Vicinarum Ephoro Fidelissimo, Tam De Sparta Perhonorifica, Quam De Nuptiis Secundis, Utinam Secundis Cum [...] Maria-Elisabetha [...] Magdalenae-Eleonorae, Lib. Baronissae De Schoenburg/ Dominae Glauchavii Et Waldenburgi, Ec. Tenus Hac a Cubiculis [...] Georgii Seyfarti, Senatoris Et Aerarii Eccles. Penicensis Praefecti, Filia Perdilecta: Glauchavii Osterlandorum D. XIIX. Octobris [...] M.DC.LXXXVI. Solenniter Celebratis. (Doppeltes Liedchen, dem verehrungswürdigen, hochverehrten Johann Caspar Harrbach, Pastor der Glauchauer Kirche und treuestem Aufseher der benachbarten [Kirchen], bei seiner zweiten Eheschließung anlässlich der Hochzeit mit Maria Elisabeth, der Kammerfrau der Magdalene Eleonore Baronin von Schönburg und Herrin von Glauchau und Waldenburg, des Georg Seyfart, Ratsherrn und Kämmerers in Penig, geliebten Tochter, in Glauchau im Osterland am 18. Oktober 1686 stattgefundenen großartigen Feier). ${ }^{34}$

32 Ratsschulbibliothek Zwickau.

33 Fleming, Deutsche Gedichte (wie Anm. 6), Poetische Wälder III, Nr. 2.

34 Ratsschulbibliothek Zwickau; Augustinuszitat Civitas Dei, 16. Buch, 34. Kapitel. 
Dem Text ist eine Frage aus der Civitas Dei des Augustinus vorangestellt, die Rechtfertigung der zweiten Ehe des Abraham, der nach dem Tod seiner ersten Frau Sara die Cethura heiratete: Quid sibi vult, quod Abraham post mortem Sarae, Cethuram duxit uxorem? Provisium hoc facto est contra haereticos futuros, secundarum nuptiarum adversarios, ut in ipso Padre multarum gentium demonstraretur, non esse peccatum, post obitum conjugis iterum conjugari. (Am Ende ist ja gerade wider Häretiker, welche Gegner einer zweiten Hochzeit werden sollten, auch dadurch Vorsorge getroffen worden, dass an keinem Geringeren als den "Vater vieler Völker" die sittliche Zulässigkeit einer weiteren Verehelichung nach dem Tode des Gatten erwiesen wurde.)

Hier wird die Ehe als eine christliche Institution aufgefasst und gefeiert. Das humanistische Lob der Liebesleidenschaft war bei dem fortgeschrittenen Alter des Brautpaares wohl unpassend, vielleicht auch theologisch nicht mehr zeitgemäß. Der lateinische Text rühmt die Amtsführung des Bräutigams. Die angeschlossenen deutschen Verse betonen ebenfalls das Alter des Bräutigams und die Mühen seines Amtes, die künftig durch den Beistand der Ehefrau leichter zu tragen sein werden:

Je höher Ebren-Stand/ je mehr sich Sorgen finden/
Die umb den Scheitel offt viel Silber-Haare winden:
Da hemmet manchen Schlaff die schwere Amptes Last/
Wenn And're Sorgen-los geniessen ibre Rast.
Herr VETTER/ Er lebt auch annietzt in hoben Ehren/
Muß viele Aufsicht hab'n/ muß straffen/ trösten/lehren/
Bey werther Vater-Stadt. Das kann nicht leichte seyn:
Noch schwerer kams ibm an/ daß er bisher allein
Mußt'/ als ein Witber noch/ die Sorg' im Hauße fübren:
Da ließ bei Müb' und Schweiß sich schlechte Freude spüren/
Die sonst/ wie Syrach 35 sagt/ ein Eb'-Weib ibrem Mann/
Wenn sie vernüfftig ist/ Vergnüglich geben kann.
Nun läßt sich's besser an: Nun kann sein Hertz erfrischen/
Und manchen Ambtes Schweiß von seiner Stirne wischen
[...].

Ob diese Verse von Pölitz oder von Förster stammen, ist nicht gekennzeichnet. Auch Harrbach war in zwei seiner drei Ehen mit Angehörigen der gehobenen schönburgischen Diener- und Beamtenschaft verheiratet. ${ }^{36}$ Johann Pölitz war 1679 dem Musikalischen Kränzchen beigetreten, ${ }^{37}$ dessen Vereinslied oben zitiert wird. Hier amtierte er dreimal als Provisor, also als Kassenverwalter, ein Zeichen seines gesellschaftlichen Ansehens. Dreimal, 1680, 1687 und 1697, hat er die Vereinsmitglieder satzungsgemäß bewirtet, das letzte $\mathrm{Mal}$ in seiner Behausung in Wernsdorf. Dieses Pfarrhaus ist ein kulturhistorisch bedeutendes Gebäude; es wurde 1564 errichtet und hat den Dreißigjährigen Krieg unbeschadet überstanden. Ab 1687 wurde jedem gestor-

35 Jesus Sirach, jüdischer Religionslehrer und Verfasser eines Abschnitts des Alten Testamentes, der sich positiv über die Ehe geäußert hat.

36 Harrbach hatte in erster Ehe 1656 Sophie Nitzsche (gest. 1681) geheiratet, die Tochter von Thomas Nitzsche, Kammerdiener und Hofschneider in Rochsburg und Bürger in Penig; Germann, Musikalisches Kränzchen (wie Anm. 27), S. 94. Er war der Sohn eines Glauchauer Stadtvogts, entstammte also selbst dieser Schicht. Seine beiden Söhne wurden Pfarrer, seine fünf Töchter Pfarrfrauen. Er besaß das Eckhaus vom Schloßplatz zur Schloßstraße; Eckardt, Chronik von Glauchau (wie Anm. 21), S. 326 f.

Germann, Musikalisches Kränzchen (wie Anm. 27), S. 95. 


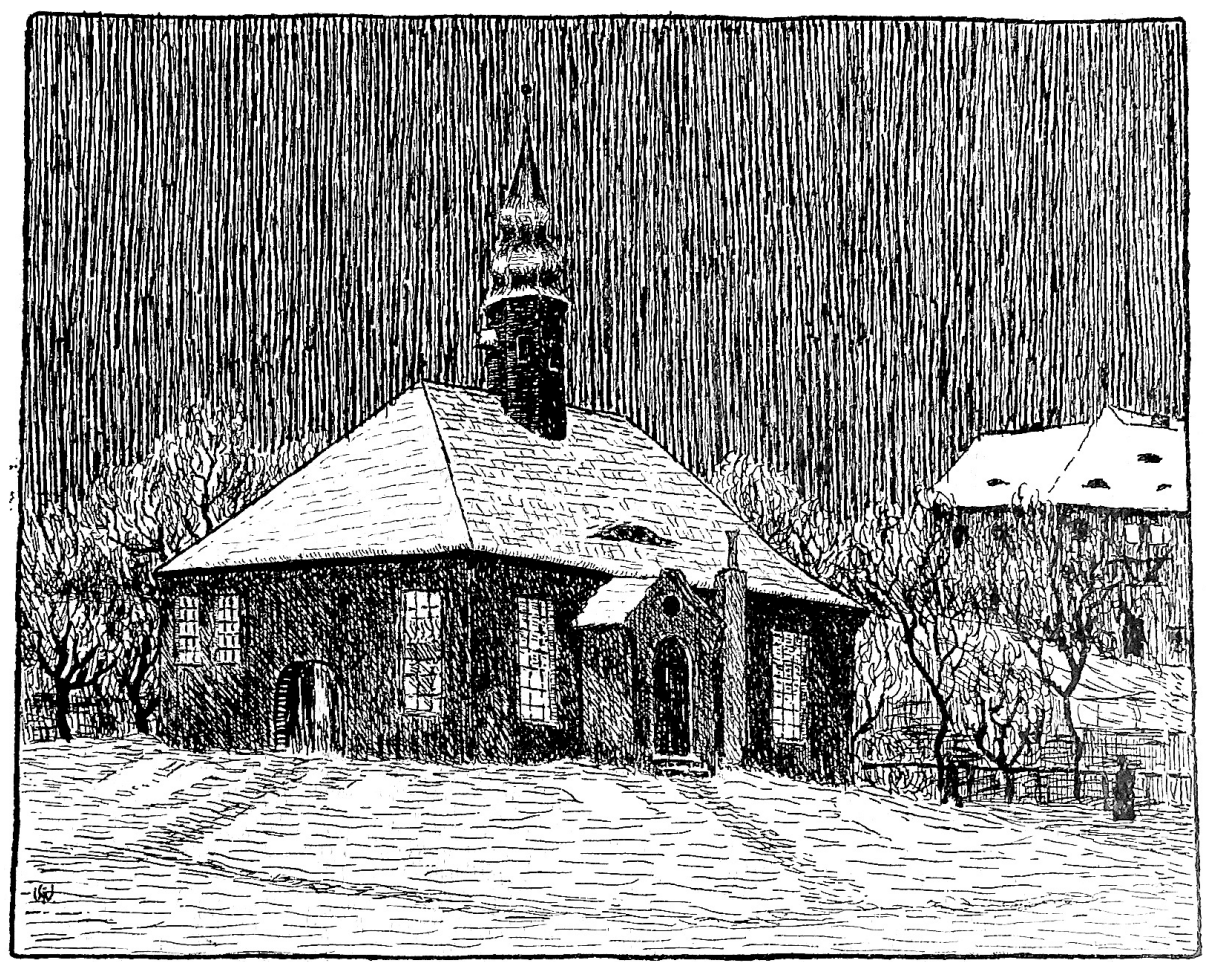

Abb. 4: Gottesackerkirche in Glauchan um 1900, 1911 abgerissen. Undatierte Strichzeichnung.

benen Mitglied des Musikalischen Kränzchens ein Totengedicht gewidmet; ${ }^{38}$ sollte Pölitz solche Gedichte beigetragen haben, so sind sie nicht überliefert.

Haben wir von Johann Pölitz selbst fast nichts über die zeitgenössische Gelegenheitsdichtung erfahren können, so ergab sich alsbald eine bessere Gelegenheit dazu. Im Jahre 1707 starb seine hinterlassene Tochter Ludomilla, ein hübsches und altkluges Kind, das durch seine demonstrative Frömmigkeit die Glauchauer Pfarrer beeindruckt hatte, im Alter von fast fünf Jahren an den Pocken, die es sich bei der Einschulung geholt hatte. Den hochtrabenden Vornamen hatte das Kind von seiner Patin, einer Schönburgerin, übernommen. Die Leichenpredigt hielt der Amtsnachfolger von Johann Caspar Harrbach, der Superintendent Johann Köhler (1672-1724) und auch der Diakon Samuel Friedrich Crusius (1681-1750) ergriff in der Glauchauer Gottesackerkirche das Wort. Beide Reden wurden gedruckt; im Anhang steuerten beide Pastoren sowie die mit der Familie befreundeten oder verwandten Pfarrer und die Brüder des Mädchens, die noch Theologie studierten, Gedichte bei. Dieser kleine Fundus von Gelegenheitsversen soll anschließend vorgestellt werden. ${ }^{39}$

Es handelt sich diesmal durchweg um geistliche, um christliche Gedichte. Der Gott des Neuen Testaments steht im Mittelpunkt. Die Theologen hatten sich unter dem Einfluss der Pietisten auf die Lehre der lutherischen Reformation zurückbesonnen; der

38 Ebd., S. 21.

39 Digitalisiert, zugänglich über das Verzeichnis der Drucke des 18. Jahrhunderts (VD18 9026133X). 
frivole Humanismus war Vergangenheit. Fast alle Autoren kommen inhaltlich von der Klage zum Trost: Der Verlust des Kindes tut weh, vor allem der Mutter, aber der Gedanke, dass es sich bereits im Paradies befindet, hebt diesen Schmerz auf. Die Theodizee, die Rechtfertigung Gottes angesichts dieses Todesfalles, gelingt mit Hilfe dieses Gedankens ohne Schwierigkeiten. Alle elf Dichter reimen deutsch, die antike Mythologie und die lateinische Sprache gehörten für die auf Johann Pölitz folgende Generation nicht mehr zum poetischen Kanon. Sie sind es gewohnt, mit der Sprache umzugehen, jeder ist wortgewandt und beherrscht das gewählte Versmaß, den Ton vieler Kirchenlieder. Das Reimschema ist einfach ab/ab oder aa/bb. Einige Dichter statten ihr Gedicht mit Anmerkungen auf die zitierten Bibelstellen oder andere Autoritäten aus, sie demonstrieren ihre Gelehrsamkeit. Sprachlich überzeugen die Verse des Superintendenten Köhler, der seine Predigt noch einmal poetisch zusammenfasst:

Ein Kind von guter Art/ das seine Seele in seine zarte Brust von Gott bekommen hat/ Das wird, ach allzufrüh! In seine Grabes Höle Und in den sanften Schooß der küblen Lagerstatt $\mathrm{Zu}$ zeitlich hingebracht. So will der Herre eilen Mit Ludomillen/ weil ibr Geist ibm woblgefällt/ Sie will auch selber fort und länger nicht verweilen Sie trachtet lediglich in jenes Freuden-Zelt

Mit Freuden einzuziehn. Ach dies erreget Schmertzen! Ach saget solches doch nicht der Frau Mutter an! Als sie dies einge Kind getragen unter Hertzen/ Daber sie selbes auch wohl nicht vergessen kan. Getrost! Was will sie sich darüber lang betrüben?

Gott holet es zu sich und seinen Freuden ein/ Zumablen/ da sie weiß/ daß denen/ die Gott lieben Müßt auch der Kinder Tod zum besten dienlich seyn.

Ein Gegenstück liefert der Amtsnachfolger von Johann Pölitz, der Wernsdorfer Pfarrer Magister Johann Francke, ${ }^{40}$ der zwar ebenfalls einigermaßen gewandt reimt, in der Wortwahl allerdings nicht so sicher ist:
[...]
Du aber warest doch zuvor ein Bild im Leiden:
Die Blattern waren dir nicht ein geringer Schmertz/
Die plagten deinen Leib wie Job ${ }^{41}$ auf allen Seiten.
Ob was vor großes Leid empfand das Mutter-Hertz!
Als nun der blasse Tod dich aus der Welt gerissen/
Der Mutter beste Freud und Trost dadurch beraubt/
In dero Herz und Seel sind Wunden tief geschmissen/
$\mathrm{Da} / \mathrm{/}$ wer es nicht gesehn/ mit mir niemahls geglaubt
Ich bitte meinen Gott, er woll die Wunden beilen/
In dieses Mutter-Hertz/ einflößen Freuden-Öl:
40 Auch Johann Francke war mit einer schönburgischen Kammerdienerin aus Remse namens Justine Schneider verheiratet; Germann, Musikalisches Kränzchen (wie Anm. 27), S. $107 \mathrm{f}$.
41 Hiob.


Er lasse den Betrübten zu keiner Zeit es feilen ${ }^{42} /$

Was nur in dieser Welt erfreuet ibre Seel!

Und auch ein jeder Christ mit mir wobl lerne kennen/

Daß alles/ was ibm Gott zuschickt auf dieser Welt/

Herrübr aus lauter Güt/ drum soll er ibn auch nennen

Den Vater/ der da thut/ was ibme woblgefällt.

Hier meldet sich nun auch der Schwager Christian Förster zu Wort, inzwischen Pfarrer an der Moritzkirche in Zwickau, und beweist, dass er zu recht vom verstorbenen Laureaten als Mitautor der Harrbachschen Hochzeitsfestschrift herangezogen worden war. Sein Gedicht zeigt poetischen Schwung und es ist für den heutigen Geschmack das Ansprechendste der ganzen Sammlung. Das Vokabular sowie der theologische Gedankengang sind jedoch nicht sehr originell:

Ach! Schade/ wenn man muß ein einig Schäflein missen/

Das man gehegt/ geliebt/ gespeist von seinem Bissen/

Aus seinem Becher auch mit Liebe hat getränckt:

Wenn das verloren gebt/ das jammert/ ach! Das kränckt.

Ein solches Schäflein hat/ Frau Schwäg'rin sie geheget:

Ihr Ludomill'gen wars/ das hat sie stets gepfleget/

Nach rechter Mutter-Art/ mit Wartung, Speis und Trank:

Und eb' an sichs versab/ lags an den Blattern kranck.

Das ging/als Mutter/ ibr nun freylich sebr zu Hertzen:

Sie hätt ihr liebstes Kind von seinen Blatter-Schmertzen

Wo möglich gern befreyt; doch es dran sterben mußt!

Nun hat sie's eingebüßt. O Schade! O Verlust!

Doch nicht so: was man hat aufs beste aufgeboben/

Das ist nicht eingebüßt/ es lebt ibr Kind schon droben/

Der Seelen nach/ bey Gott/ da ibm keyn Schmertz bewußt/

Wo keine Kranckheit ist/ kein Schade/ kein Verlust/

Frau Schwäg'rin drum getrost! Gönnt doch die Himmels-Weydel

Die Jesus Schäflein dort/ in lauter Lust/ und Freude/

Geniessen immerdar/ dem seelgen Töchterlein

Gott läßt auch solcher Lust uns einsten fähig seyn!

Der Bruder der Mutter, Christoph Scharschmidt, Diakon in Mutzschen, ${ }^{43}$ gedenkt in seinem Gedicht auch des verstorbenen Vaters, des gekrönten Poeten:

[...]

Ich höre noch dein Ach! Ich seb der Hände Ringen/

$D a$ dir dein Eb-Herr starb/ den Wernsdorff so geliebt/

Und dieses seelgen Manns so leicht nicht wird vergessen/

Weil er als Hirte sie zur besten Weyd gefübrt/

Du hast als Wittwe bald fünff Jahr im Leid gesessen/

Und sieb der Tochter Tod dein Hertz aufs Neue rübrt.

Drum kann ich nichtes nicht als Thränen an dich schreiben/

Denn deinen Thränen leg ich billich Thränen bey

Ich weiß fast keinen Trost vor Jammer aufzutreiben/

42 Fehlen.

43 Mutzschen, heute Stadtteil von Grimma. 
So nabe gebt es mirl ich schreib es obne Scheu.

[...]

Ein Neffe der Mutter, auch ein Pölitz und der Theologie beflissen, trug den originellen Gedanken bei, dass ein verstorbenes Mädchen den Verführungen der Welt noch nicht ausgesetzt sein konnte und schon deswegen zu preisen ist:

Was ist doch wobl die Welt? Ein Labyrinth der Seelen/

Da Manche als verfübrt nach Fall und Unglück strebt.

Wobl! Daß mein Seelen-Freund mich bald aus dieser Hölen

$\mathrm{Zu}$ sich in Himmel nabm/ wo man recht glücklich lebt.

Die Bezeichnung der Welt als ein Labyrinth der Seelen hört sich merkwürdig modern an, kommt allerdings bereits im Frühbarock als emblematischer Topos vor. ${ }^{44} \mathrm{Im}$ Fußboden gotischer Kathedralen sind Labyrinthe eingelassen als Sinnbilder der Welt, in der sich die Seele verirren kann. Der Verfasser dieser Zeilen war nicht nur ein gebildeter Mensch, sondern es kommt auch hier eine andere Weltsicht zum Ausdruck, als sie Fleming und Vater Pölitz poetisch vertreten hatten: Die Welt ist eine Lasterhöhle; Sexualität ohne den Segen der Kirche führt ins Unglück.

Pfarrer Crusius hatte dem Kind bereits am Ende seiner Trauerrede eine Grabinschrift gewidmet, dessen Reim nur im sächsischen Dialekt funktioniert:

Hier liegt ein liebes Kind/ das ist zwar aus den Augen/

Nicht aber aus dem Sinn/denn weil es Gott gedient/

So wird seyn Tugend-Rauch niemals bei uns verrauchen/

Die Seele dort bey Gott in schönster Zierde grünt.

Selbst in diese Thematik hat sich die unfreiwillige Komik eingeschlichen.

Am Schluss dieses Abschnitts soll noch einmal Paul Fleming zu Wort kommen. Seine wenigen Worte, die er ja nicht diesem Glauchauer, sondern 1635 einem anderen Kind gewidmet hat, ${ }^{45}$ kennzeichnen den großen Unterschied einer sowohl inhaltlich als auch formal eigenständigen, bedeutenden Dichtung zu den Gelegenheitsreimen der Glauchauer Pfarrer:

\section{Auf den Tod eines Kindes}

Was beseufzt man so ein Kind.

So viel tapfrer Helden sterben,

Ganze Völker gar verderben,

Und die Zeit verstiebt wie Wind;

Wie soll denn ein Mensch bestehn?

Muß dies Ganze doch vergehn.

Schlafe wohl! Wir Armen, wir

Bleiben, was wir immer waren:

Jung von Weisheit, alt von Jabren,

44 Die christliche Seele im Labyrinth der Welt. Kupferstich des Boethius von Bolswart (1580-1634), Emblem im Erbauungsbuch „Pia desideria“ von Hermann Hugo (15881629).

45 Fleming, Deutsche Gedichte (wie Anm. 6), Oden II, Nr. 15. 
Unverständig für und für, Stumm an Mund, an Augen blind, Kinder, wie wir kommen sind.

\section{Johann Friedrich Käufler}

Schriftsteller im engeren Sinne des Wortes hat Glauchau wohl kaum besessen, befand Ernst Eckardt im Jahre 1881. Immerhin konnte er den bedeutenden Journalisten, Lexikografen und landeskundlichen Autor Albert Schiffner (1792-1873), der weder in der schönburgischen Residenzstadt Glauchau geboren noch gestorben ist, aber zweimal für längere Zeit dort gelebt hat, unter dieser Rubrik verbuchen. Andere literarische Erscheinungen versprach er an geeigneter Stelle zu erwähnen. ${ }^{46}$ Deshalb erscheint erst auf S. 703 der Hartensteiner Pfarrer Johann Friedrich Käuf(f)ler (1733-1816), der Sohn eines Glauchauer Kaufmanns, der bereits als junger Mann einen Gedichtband und verschiedene Prosaschriften veröffentlicht habe und deshalb mit dem Titel Caesareus poeta laureatus ausgezeichnet worden sei. Auch von dem dritten preisgekrönten Glauchauer Dichter sind nur wenige Arbeiten der Nachwelt erhalten geblieben. Er wurde 1733 als Sohn des Kaufmanns Johann Friedrich Käufler in Glauchau geboren, besuchte hier die Lateinschule und studierte in Altenburg und in Leipzig. Eckardt berichtet über ihn, er war erst Winkelschullebrer, 1776 wurde er Diaconus in Hartenstein und kam 1786 als solcher nach Lichtenstein, ${ }^{47}$ wo er 1816 starb. Schon vor seiner Anstellung batte er "Vermischte Gedichte“, dann "Abbandlungen und Gedichte in Beiträgen zu nützlichen und angenebmen Wissenschaften“, endlich "Sammlungen schöner Handlungen zur Bildung eines edlen Herzen in der Jugend" herausgegeben. Dafür wurde er am Tage seiner Hochzeit mit des Diaconus Stöckhardt ältester Tochter vom Regierungsdirektor M. Schulthes „als kaiserlichen Pfalzgrafen" mit dem poetischen Lorbeerkranz bedacht, indem er zugleich den Titel "Caesareus poeta laureatus" erbielt. ${ }^{48}$

Hier sind einige Details zu ergänzen. Seiner Biografie in zeitgenössischen Handbüchern zufolge ${ }^{49}$ war Käufler von 1757 bis 1770, also nicht weniger als 13 Jahre, Hauslehrer in Niederlungwitz bei Glauchau in der dasigen Vodelischen Papiermüble. 50 Da es dann mit einem Diakonat wohl nicht geklappt hatte, unterrichtete er in seinem Elternhaus in Glauchau als Privatmann einige Kinder. Von 1772 bis 1777 war er Baccalaureus und dritter Kollege an der Stadtschule zu Glauchau, also kein irregulärer Winkelschullehrer mehr. Dann amtierte er von 1777 bis 1786 als Hof- und Stadtdiakon in Hartenstein. In dieser Zeit veröffentlichte er ab 1779 anonym vier Teile mit erbaulicher Kurzprosa „Sammlung schöner Handlungen zur Bildung eines edlen Herzens in der Jugend“; sie sollten Eltern, die ihren halbwüchsigen Kindern die Lektüre unsitt-

46 Eckardt, Chronik von Glauchau (wie Anm. 21), S. 39 f.

47 Richtig: nach Lößnitz.

48 Eckardt, Chronik von Glauchau (wie Anm. 21), S. 39 f. - Käufler kommt auch bei Händel vor; ein Pölitz war sein Taufpate.

49 Friedrich August Weiz, Das gelehrte Sachsen oder Verzeichnis derer in den Churfürstl. Sächs. und incorporirten Ländern jetztlebenden Schriftsteller und ihrer Schriften, Leipzig 1780; Dietmann, Kirchen- und Schulgeschichte (wie Anm. 24), S. 296-298.

Die Papiermühle in Niederlungwitz war ein stattliches Anwesen, dessen Hauptgebäude 1741 neugebaut und das 1742 für 2000 Gulden innerhalb der Familie Vodel weitergereicht worden war. In der fraglichen Zeit war der Besitzer Ernst Friedrich Vodel; Germann, Musikalisches Kränzchen (wie Anm. 27), S. 133, 150. 


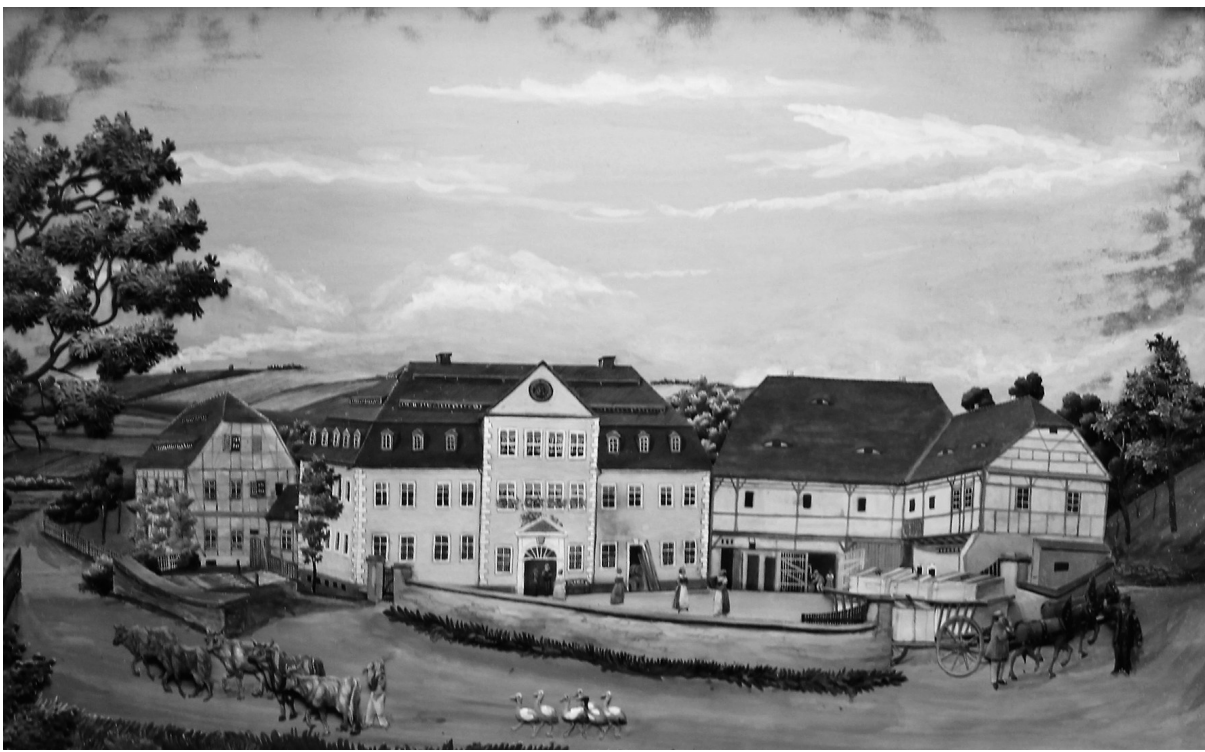

Abb. 5: Papiermüble in Niederlungwitz um 1750, undatierte kolorierte Zeichnung, Künstler unbekannt.
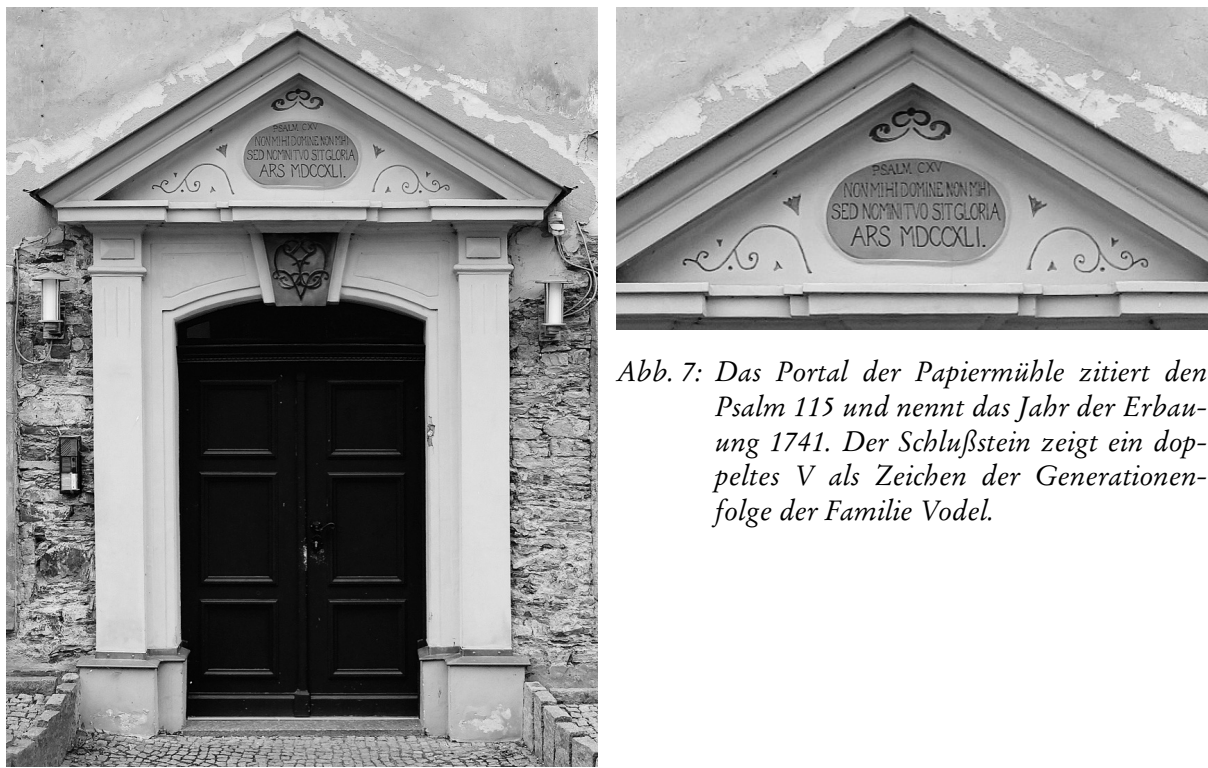

Abb. 7: Das Portal der Papiermüble zitiert den Psalm 115 und nennt das Jahr der Erbauung 1741. Der Schlußstein zeigt ein doppeltes $V$ als Zeichen der Generationenfolge der Familie Vodel.

Abb. 6: Das klassizistische Portal des Hauptgebäudes der Papiermüble in Niederlungwitz. 
licher Romane verboten, davon überzeugen, dass es auch moralisch-lehrhafte, jugendgeeignete Lektüre gab. ${ }^{11}$ Der Verleger Gottlob Emanuel Richter in Altenburg war der Sohn von Käuflers Amtsvorgänger Gottlob Ludwig Richter in Hartenstein; letzterer hatte höchstwahrscheinlich die Verbindung vermittelt. Ein in Arbeit befindliches Manuskript „Schilderungen der Zärtlichkeit oder rührende Stellen aus der Geschichte der Menschheit“ ist wohl nicht zum Druck gelangt. Seit 1786 wirkte Käufler in Lößnitz, der Hauptstadt der Grafschaft Hartenstein. Das dortige Kirchenbuch berichtet über ihn: Er war ein Wunder der Gesundheit bis vier Tage vor seinem Tode und verwaltete sein Amt bis dahin mit besonderer Munterkeit und Betriebsamkeit. Er hatte einen gewissen Gleichmut, sodass ihn weder Freud noch Leid angriff. ${ }^{52}$

Noch deutlicher als bei Pölitz handelte es sich bei Käufler um eine verspätete und abgebremste Karriere. Seine beiden Gedichtbände, die völlig verschollen sind, brachte er als 30-Jähriger 1763 oder 1764 in Leipzig und in Chemnitz heraus. Bei seiner ersten Anstellung als Lehrer in Glauchau war er schon 39 Jahre alt. Sein erstes geistliches Amt bekam er mit 44 Jahren und weiter als bis zur Eingangsstufe, zum Diakon, hat er es auch in Lößnitz nicht gebracht. Das Dichtertum (oder ein studentisches Leben als Bohemien?) war offensichtlich keine Empfehlung für das Pfarramt.

Den Titel als gekrönter Dichter erhielt Käufler 1774, als er Friederike Charlotte Stöckhardt (1752-1818) heiratete, die Tochter von M. Gottfried Gerhard Stöckhardt (1721-1788), Diakon in Glauchau von 1750 bis $1788^{53}$. Der Direktor der schönburgischen Regierung in Glauchau, der Magister Friedrich Gottlob Schulthes (Lebensdaten unbekannt), war als kaiserlicher Hofpfalzgraf zu dieser Ehrung berechtigt, ${ }^{54} \mathrm{ob}$ er freilich ein Literaturkenner war, ist eher fraglich. Vielleicht fiel ihm kein anderes Hochzeitsgeschenk ein.

Als Druck von vier Blatt überliefert ist eine Hommage, die Käufler dem Glauchauer Geistlichen M. Christoph Gottlob Grundig (1707-1780) gewidmet hat. ${ }^{55}$ Grundig war ein bedeutender sächsischer Gelehrter und Schriftsteller, aber er gehörte nicht zur Glauchauer Literaturszene, sondern zur Freiberger. ${ }^{56} \mathrm{Er}$ war Oberpfarrer in Schneeberg gewesen und wurde 1758 als Superintendent nach Glauchau berufen. Wegen seiner Leidenschaft für Mineralogie und Bergwesen ging er schon im folgenden

51 Den ersten Teil, der als solcher nicht gekennzeichnet ist, hat mir die Herzogin Anna Amalia Bibliothek Weimar zugänglich gemacht. Er enthält auf 184 Seiten 38 Kurzgeschichten von erbaulichen Handlungen tugendhafter Personen, deren Quellen und Verfasser oft nicht genannt werden. Zum Teil sind es zeitgenössische Anekdoten; nur wenige Geschichten stammen aus der Bibel, viele aus der römischen und griechischen Geschichte oder aus der antiken Mythologie. Käuflers Name taucht darin nicht auf.

52 Händel, Vorfahren (wie Anm. 28).

53 EckardT, Chronik von Glauchau (wie Anm. 21), S. 341. - Die Stöckhardts waren eine bekannte sächsische Schriftsteller- und Gelehrtenfamilie. Der wichtigste Vertreter war der Jurist Heinrich Robert Stöckhardt (geb. Glauchau 1802, gest. St. Petersburg 1848), der auch musisch begabt war.

54 Nicht bei Eckardt, Chronik von Glauchau (wie Anm. 21; Dietmann, Kirchen- und Schulgeschichte (wie Anm. 24), S. 9. - Nicht zu verwechseln mit Johann Friedrich Schulthes, der 1807 Regierungsdirektor in Glauchau war; ECKARDT, Chronik von Glauchau (wie Anm. 21), S. 689.

55 Digitalisiert (VD18 10570284) - Flood, Poets laureate 2 (wie Anm. 1), S. 969 schreibt Käufler noch eine lateinische Huldigungsschrift zu, welche drei sächsische Theologen Grundig gewidmet haben. Käufler ist aber nicht darunter: De precibus, quae fiunt [...] disserunt et simul [...] Christophoro Gottlieb Grundigio antistiti hactenus sacrorum Glauchensium [...] congratulantur [...], Freiberg [1759].

56 Ausführlich bei Dietmann, Kirchen- und Schulgeschichte (wie Anm. 24), S. 95 ff. 
Jahr nach Freiberg, wo er bei der Gründung der Bergakademie mitwirkte. Es gelang ihm und den ihm unterstellten Pfarrern unter anderem, das damals gängige Gesangbuch für die Lebenswelt der Bergleute vollständig umzudichten. ${ }^{57}$ Anlässlich seines Abzugs aus Glauchau schrieb Käufler folgende Verse:

Heil, Heil dem Manne, der den Herrn

Von ganzem Herzen liebt!

Dem Christ! Der seine Pflichten gern

Nach Gottes Vorschrift übt.

Den Tugend und Religion

Zum Menschenfreunde macht;

Der über aller Spötter Hohn

Sich hebt, und sie nicht acht.

Heil dem, der nie der Laster Freund,

Nie Knecht der Lüste ist;

Mit Gott und Mensch es redlich meint,

Und Gottes Wort oft liest.

Es folgt der Vergleich mit einem Baum, der Schatten spendet, den der Herr vor dem Sturm bewahrt und an anderer Stelle wieder einpflanzt:

Da wurzeln sie und wachsen hoch,

Wie Cedern Libanon;

Sind unentlaubt und blüben noch,

Nabt auch das Alter schon.

Der Du, geprießner Gottesmann,

Nicht lange uns gelehrt,

Der Gott hat auch an Dir gethan,

Wie er die Frommen ehrt.

[...]

Und ... Stammelt gleich der blöde Mund,

Und zittern Kiel und Hand;

Gnug! Mach ich doch die Ehrfurcht kund,

Die ich für Dich empfand.

Das sind biedere und gesinnungstüchtige, aber sprachlich und im poetischen Einfall durchschnittliche Verse. Weitere Gedichte und Abhandlungen von Johann Friedrich Käufler sind in einer Zeitschrift enthalten, die Christoph Gottlob Grundig 1772/73 in Freiberg herausgeben hat: „Nützliche Beyträge zu den nöthigen und angenehmen Wissenschaften“. Der Superintendent und der Diakon sind also weiterhin in Verbindung geblieben. Grundig hatte einen kleinen Beitrag zu dem Stein am „Gebel el Mokatab" veröffentlicht, wozu J. F. K. eine Nachlese verfasste. Es handelte sich um einen mit seltsamen Zeichen bedeckten Stein, der am Berg Sinai entdeckt und unter Geologen und Theologen diskutiert worden war. Käufler bringt eine Abbildung und Beschreibung des Steins und referiert die älteren Deutungen, beginnend mit derjenigen des Jesuiten Athanasius Kircher, der chaldäische Schriftzeichen mit der Prophezeiung

57 Neueingerichtetes Freybergisches Gesangbuch [...], Freiberg [um 1780]. 
eines von Gott gezeugten und von einer Jungfrau geborenen Kindes entziffert haben wollte. Die anderen Vermutungen ungenannter Verfasser reichen von der Ortsangabe, wo sich die jüdische Bundeslade befindet, bis zur Auskunft, Moses habe die Zeichen höchstpersönlich eingeritzt und ihnen die Gebeimnisse der Erlösung des menschlichen Geschlechts anvertraut. Käuflers eigener Beitrag ist ein Hinweis auf eine geografische Arbeit, wonach über diesem Steine öfters ein großes Licht und heller Glanz gesehen werden. ${ }^{58}$ Der Herausgeber Grundig fügte noch eine skeptische Anmerkung hinzu, dass es sich bei diesem Stein auch um eine Fälschung der Mönche des Catharinenklosters handeln könne, um sich und diesen heiligen Orten ein größeres Anseben zu geben. ${ }^{59}$

Der Theologe Käufler hatte sich vermutlich nur deswegen für den seltsamen Stein interessiert, weil dort angeblich besondere Lichterscheinungen aufgetreten waren. Als Hauslehrer hatte er einen Meteor beschrieben, den er zusammen mit einem Freund am 23. Juli 1762 viertel auf $11 \mathrm{Ubr}$ auf einem Fußmarsch von Hohenstein nach Glauchau beobachtet hatte. Sie wurden durch einen hellen Schein aufmerksam und sahen einen Stern in der Größe des Abendsterns, welcher zusehens grösser ward, in dessen Centro ein schneeweisses Feuer recht zu wallen schien, und das ausserordentliche Licht auf den Erdboden warf. Wir bemerkten eigentlich keinen feurigen Schweif, sondern nur einen schwachen und blassen weissen Schein neben und hinter ibm. Und in dem Augenblick, $d a$ wir ibn betrachteten, fing er an, am Horizonte bin zu laufen und kam uns hinter einem Berge aus dem Gesichte. Sein erster Standort war [von] uns mebr gegen den Norden als Westen und er lief sodann mebr nach Osten als Norden. So lange wir ibn saben (und das dauerte über eine Minute) bebielt er die Sternenforme und das weisse leuchtende Licht oder Feuer, und wir saben ibn auch nicht zerspringen, noch vielweniger hörten wir einen Knall, sondern er spritzte nur, ehe er sich aus unserem Horizonte verlor, einige wenige Funken von sich, die aber noch lange nicht die Gestalt und die Figur von Raqueten hatten. Ich vermute, dass er im Verfolg seines Laufs die Sternform verloren, die Ecken und Winkel, unserem Augenschein nach, muß ausgefüllet und die Kugelform erhalten haben. ${ }^{60}$ Käufler hatte in den Leipziger Zeitungen gelesen, dass man auch andernorts diesen Meteor gesehen hatte, und teilte nun seine Eindrücke mit. Sein Niederlangwitz ${ }^{61}$ bey Glauchau im Schönburgischen, den 24. August, 1762 abgefasster Bericht weist ihn als einen guten Beobachter und Protokollanten aus. Weitere Abhandlungen von ihm sind angeblich in zeitgenössischen Monatsschriften zu finden. ${ }^{62}$ Offensichtlich war er nicht nur ein Poet, sondern auch ein interessierter Naturwissenschaftler.

Die „Nützlichen Beyträge“ überliefern uns noch zwei Verserzählungen des jungen Käufler. Das erste „Der edelmüthige Husar. Eine wirkliche Begebenheit“ erzählt eine Anekdote aus dem Siebenjährigen Krieg, in dem preußische Truppen Sachsen besetzt hatten. Ein preußischer Husar, mit zwei Kameraden auf Rekognition unterwegs, sieht,

58 Dappers Beschreibung der Landschaft Arabien p. 368. Welche der vielen geografischen Veröffentlichungen über Afrika und Kleinasien von Olfert Dappert gemeint war, konnte nicht ermittelt werden.

59 Nützliche Beyträge zu den nöthigen und angenehmen Wissenschaften, Freiberg/Leipzig 1772, S. 304-372. Kopien dieser Texte vermittelte mir die Universitäts- und Landesbibliothek Sachsen-Anhalt. - Die sogenannten protosinaitischen Schriftzeichen gelten heute als eine Frühform des Alphabets und als entziffert.

60 Merkwürdige Beschreibung der Erde. Nach der Mathematick, Frankfurt am Main/ Leipzig [1763], S. 116 f.; Bayerische Staatsbibliothek.

61 Richtig: Niederlungwitz.

62 Weiz, Gelehrtes Sachsen (wie Anm. 49). 
dass auf einem Hügel andere Husaren, also seine Kameraden, den Wagen eines Plauener Kaufmanns plündern wollen. Er stellt fest, dass er selbst beim Bruder dieses Fabrikanten im Quartier gelegen hat und bezichtigt die anderen Husaren, Straßenräuber zu sein. Preußische Soldaten tun so etwas nicht!

Sie, die an Zabl ibm überlegen waren,

Verdroß der Schritt, den er aus Großmuth that,

und gaben trotzig ibm den Rath,

Er solle seine Straße reisen

Wo nicht, so würde man ihm bald die Wege weisen.

Sie setzten sich zu Pferd und machten sich parat

Zum blutigsten Gefecht, um sich um diesen Wagen

Ergrimmt mit ihm herum zu schlagen.

Der Held wird dieß gewabr, giebt einen Wink und sprengt

Mit einem Muth, den nur die Tugend schenkt,

Den Säbel in der Faust, mit aufgezognem Habn

Gerad auf jene los, schrie sie gebietrisch an:

„Trotz! Wer nur Miene macht und setzt sich mir zuwider,

Den schießen ich und meine braven Brüder,

Als einen Hund, hier auf der Stelle nieder!

Packt gleich die Coffres auf, und dann entfernet euch!

Sie thatens und entfernten sich zugleich.

Eine Belohnung lehnt der wackere Soldat ab, er erbittet sich jedoch spätere Fürsorge von dem geretteten Fabrikanten:

Allein, so bald der Krieg zu Ende,

Und ich bin nicht ganz Krüpel oder todt,

Dann näbr ich mich der Arbeit meiner Hände,

Und dann verschaffen sie mir Brod. ${ }^{63}$

Diese rührende Geschichte hat eine leicht sozialkritische Tendenz. Die vornehmen Herren sollen wissen, dass Edelmut und Redlichkeit auch bei einfachen Leuten vorkommen:

Und doch, bey aller Seltenheit,

Sind sie kein Eigenthum nur blos des hohen Standes,

Des Ueberschlags, der Scherp', des Ordensbandes,

Man trifft ein redlich Herz auch beym geringsten Mann

So gut, als bey den Hoben an.

Dass hochgestellte Leute auch die Ursache von Schandtaten sein können, eher noch als geringe Leute, das ist diesmal noch nicht das Ziel. Dieses brav gereimte, sprachlich aber nicht sonderlich originelle Gedicht fand offensichtlich viele Leser; es wurde von einer Hamburger Zeitschrift übernommen, aber ohne Angabe des Verfassers. ${ }^{64}$

Die zweite Verserzählung trägt den Titel „Die Spinnwebe“. Das vorangestellte Motto lautet: Aranea manibus net atque carpit, Et in regiiis degit palatiiis (Die Spinne

63 Nützliche Beyträge (wie Anm. 59), S. 372-377.

64 Taschenbuch zur angenehmen und nützlichen Unterhaltung, Hamburg 1786, S. 229233. 
arbeitet und ernährt sich mit ihren Händen, und lebt [trotzdem] in den Palästen der Könige). ${ }^{65}$ In einen Saal baut eine Spinne ihr Netz. Kaum ist es fertiggestellt, reißen die großen Fliegen Löcher hinein, aber eine kleine Fliege, die das auch versucht, bleibt darin hängen und fällt der Spinne zum Opfer. In diesem ausführlichen, nicht weniger als vier Druckseiten umfassenden Gedicht ist die philosophische und sozialkritische Tendenz offenkundig. Die Natur, die durch die Spinne tätig wird, liefert ein vollkommeneres Gebilde als der Architekt, der den aufgeputzten Saal entworfen hat. Und die politische Lehre ist eindeutig:

Wem gleicht das Bild der Spinneweben?

Gesetzen, die die Fürsten geben,

Und die ein Großer schon am ersten Tage bricht,

Und ungestraft es thut. Laß nun dieselbe Pflicht

Den Niedern künftig einmal brechen,

Stracks wird sich das Gesetz an ibm mit Strenge rächen.

Der Kleine nur wird allezeit

Das Opfer der Gerechtigkeit.

Käufler entpuppt sich hier als Aufklärer, der ein Jahrzehnt vor der Französischen Revolution die herrschende Gesellschafts- und Rechtsordnung in Frage stellt. Form und Methode hat er bei Johann Fürchtegott Gellert entliehen, die Tendenz bei Jean Jacques Rousseau. In den beiden Verserzählungen des Studenten kommt der christliche Gott nicht vor, stattdessen eine römische Göttin:

Wer weiß, ob nicht die Spinne gar

Die stolze Weberinn Arachne selber war,

mit der Minerven selbst einst lieber um die Wette

Gesponnen und gewebet bätte,

Nur daß ibrs nicht bekam. 66

Hier spricht nicht der Theologe, sondern der kritische Intellektuelle. Auch das ist möglicherweise ein Grund, weshalb es mit der Anstellung im Pfarramt nicht so schnell ging. Unter den wenigen Gedichten, die von Käufler überliefert sind, ist dieses das beste. Es lässt ahnen, dass er den Titel des Poeta laureatus nicht ohne zureichenden Grund getragen hat.

Dass Käufler ein preisgekrönter Dichter war, weiß man heute nicht mehr. In Hartenstein vollbrachte er die Tat, der er seine heutige Bekanntheit verdankt: Er entdeckte durch systematische Suche 1778 die Prinzenhöhle wieder, die Felsspalte, in der im Juli 1455 zwei Kumpane des Kunz von Kaufungen den entführten sächsischen Kurprinzen Ernst versteckten. Sein Motiv zu dieser Suche war angeblich, dass er für eine bevorstehende Hochzeitsfeier im Hause Schönburg einen Beitrag leisten wollte, und tatsächlich fand bei dieser Gelegenheit 1779 eine Lustbarkeit vor der Höhle statt. ${ }^{67}$ Käufler

65 Die Herkunft dieses Spruches konnte nicht ermittelt werden.

66 Nützliche Beyträge (wie Anm. 59), S. 554-558. Die Weberin Arachne besiegte die Göttin Athene (römisch: Minerva) in einem Wettstreit an Kunstfertigkeit und wurde zur Strafe in eine Spinne verwandelt.

67 Jürgen HüLler, Der Prinz-Ernst-Stollen, die andere „Prinzen-Höhle“, Wikipedia 2012. 
hat also zu Ehren seiner Dienstherren nicht gedichtet, sondern historisch-geografisch geforscht. Mit seiner weltlichen Obrigkeit hatte er sich also abgefunden.

\section{Zusammenfassung}

Einen neuen Paul Fleming konnte dieser Beitrag nicht vorweisen, sondern nur einen Überblick über die Gebrauchs- und Gelegenheitsdichtung des 17. und des 18. Jahrhunderts in den schönburgischen Territorien. Bei der langgestreckten Form der schönburgischen Besitzungen, die vom Erzgebirge bis in die nordsächsische Ebene reichten und niemals zu einer einheitlichen rechtlichen Form gefunden haben, war ein literarisches Milieu hier gar nicht zu erwarten. Die wenigen regionalen Talente wurden in den Universitätsstädten entdeckt und geprägt; in der Provinz versiegte ihre Begabung oder sie wurde nicht ausreichend gefordert. Aber auch diese Literaten fügten sich in die Geistesgeschichte ihres Jahrhunderts ein. Auch sie reproduzierten den Wandel der Weltanschauung von der Renaissance zur Aufklärung und zum Pietismus und verliehen ihm einen überzeugenden Ausdruck. Sie waren Gestalter des jeweiligen Bildungshorizontes, zum Teil auch von persönlichen Stimmungen und Gemütsbewegungen. Auch das ist ein Kapitel der Literaturgeschichte.

In Müllers Mystifikation sehe ich dessen versteckte Kritik an der Diskussion über den ersten Band seiner Schönburgischen Hausgeschichte. ${ }^{68}$ Müllers Kritik an seinen Kritikern als Schildbürger erreicht hiermit ihre Adressaten. ${ }^{69}$

68 Vgl. Conrad Müller, Schönburg. Die Geschichte des Hauses bis zur Reformation, Leipzig 1931.

69 Vgl. hierzu Rовву Jолснім Göтze, Günther Fürst von Schönburg-Waldenburg, Glauchau 1997, S. 54. 